\title{
Mental States in Moving Shapes: Distinct Cortical and Subcortical Contributions to Theory of Mind Impairments in Dementia
}

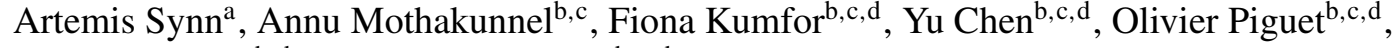 \\ John R. Hodges ${ }^{\mathrm{b}, \mathrm{d}, \mathrm{e}}$ and Muireann Irish $^{\mathrm{b}, \mathrm{c}, \mathrm{d}, *}$ \\ ${ }^{a}$ School of Psychology, Macquarie University, Sydney, Australia \\ ${ }^{\mathrm{b}}$ Brain and Mind Centre, The University of Sydney, Australia \\ ${ }^{\mathrm{c}}$ School of Psychology, The University of Sydney, Australia \\ ${ }^{\mathrm{d}}$ Australian Research Council Centre of Excellence in Cognition and its Disorders, Australia \\ e Sydney Medical School, The University of Sydney, Australia
}

Accepted 15 September 2017

\begin{abstract}
Impaired capacity for Theory of Mind (ToM) represents one of the hallmark features of the behavioral variant of frontotemporal dementia (bvFTD) and is suggested to underpin an array of socioemotional disturbances characteristic of this disorder. In contrast, while social processing typically remains intact in Alzheimer's disease (AD), the cognitive loading of socioemotional tasks may adversely impact mentalizing performance in AD. Here, we employed the Frith-Happé animations as a dynamic on-line assessment of mentalizing capacity with reduced incidental task demands in 18 bvFTD, $18 \mathrm{AD}$, and 25 age-matched Controls. Participants viewed silent animations in which geometric shapes interact in Random, Goal-Directed, and ToM conditions. An exclusive deficit in ToM classification was observed in bvFTD relative to Controls, while AD patients were impaired in the accurate classification of both Random and ToM trials. Correlation analyses revealed robust associations between ToM deficits and carer ratings of affective empathy disruption in bvFTD, and with episodic memory dysfunction in AD. Voxel-based morphometry analyses further identified dissociable neural correlates contingent on patient group. A distributed network of medial prefrontal, frontoinsular, striatal, lateral temporal, and parietal regions were implicated in the bvFTD group, whereas the right hippocampus correlated with task performance in AD. Notably, subregions of the cerebellum, including lobules I-IV and V, bilaterally were implicated in task performance irrespective of patient group. Our findings reveal new insights into the mechanisms potentially mediating ToM disruption in dementia syndromes, and suggest that the cerebellum may play a more prominent role in social cognition than previously appreciated.
\end{abstract}

Keywords: Cerebellum, dementia, hippocampus, medial prefrontal cortex, mentalizing, social cognition, striatum

\footnotetext{
${ }^{*}$ Correspondence to: Muireann Irish, School of Psychology and Brain \& Mind Centre, The University of Sydney, 100 Mallett Street, Camperdown, NSW 2050, Australia. Tel.: +61 291144165 ; E-mail: muireann.irish@sydney.edu.au.
}

\section{INTRODUCTION}

Human social behavior is governed largely by the capacity to construct a "Theory of Mind" (ToM), enabling us to infer the thoughts, beliefs, and feelings of others [1]. This aptitude to consider perspectives distinct from our own appears to be so ubiquitous that 
we spontaneously attribute human character traits and ascribe mental states to inanimate shapes devoid of any of the facial, emotional, or social cues present in everyday social scenarios [2,3]. In recent years, there has been a surge in research interest seeking to clarify the neurobiological substrates of ToM using functional neuroimaging techniques (reviewed by [4]) and to delineate how alterations to this complex process relate to the emergence of maladaptive social behaviors [5]. Here we explore the neural substrates of ToM impairments in younger-onset dementia.

The behavioral variant of frontotemporal dementia (bvFTD) presents a striking illustration of the degeneration of the "social brain" [6]. This form of younger-onset dementia is characterized initially by marked changes in behavior and personality, manifesting in executive dysfunction, emotion dysregulation, and dramatic impairments in interpersonal functioning [7]. A profile of emotional blunting, decreased empathy, loss of social interest, and diminished responsiveness to the feelings of others is commonly observed [8-12] resulting in florid violations of social norms, decreased tact, loss of empathy, and reduced interpersonal responsiveness [13, 14]. These changes are attributable to characteristic brain atrophy which originates in medial prefrontal, frontoinsular, and paralimbic structures and encroaches in a predictable fashion into adjacent prefrontal and anterior temporal regions [15-17].

The pervasive deficits in social function observed in bvFTD have been suggested to reflect the specific vulnerability of a core mentalizing mechanism subserved by the frontal lobes [18-20]. This hypothesis is supported by converging evidence of marked ToM impairments in bvFTD across an array of experimental paradigms including first- and second-order false-belief tasks [19, 21-24], cartoon tasks requiring social inferences $[8,25,26]$, tests of faux pas recognition [27-30], and ecologically valid tasks which require social inference to detect sarcasm in conversation $[31,32]$. Consistent with the early medial prefrontal cortex (PFC) and frontoinsular atrophy in bvFTD, affective ToM (i.e., attributions of emotions and feelings) appears to be uniquely vulnerable in the initial stages of the disease, followed by the emergence of cognitive ToM deficits (i.e., attributions of beliefs and intentions) [33, 34].

In contrast, socioemotional functioning tends to remain relatively intact in Alzheimer's disease (AD), at least in the early stages of the disease trajectory, despite marked impairments in episodic memory, language, and visuospatial abilities [31,35]. Although a number of studies have revealed social dysfunction in $\mathrm{AD}$, these deficits appear to manifest predominantly as a product of general cognitive dysfunction, rather than reflecting a primary impairment in specific social or affective cognitive processes per se (see $[9,25,36])$. A recent meta-analysis concluded that, even when present, ToM deficits in AD are typically less severe than in bvFTD, and modest when considered relative to overall cognitive impairment [37]. Consequently, it has been suggested that ToM measures may be well-suited to differentiate between $\mathrm{AD}$ and bvFTD [38], particularly in light of mounting evidence pointing to prominent memory impairments in bvFTD $[39,40]$ and executive dysfunction in AD $[41,42]$.

The multifaceted nature of ToM, and its reliance on several interacting social processes [43-45], renders the selection of appropriate tasks in clinical populations particularly challenging. In the context of bvFTD, task demands must be considered given conflicting findings regarding the extent to which ToM processes relate to executive dysfunction [46] and semantic impairments $[25,47]$ in this syndrome. As yet, there remains no firm consensus on how best to capture the inherently complex nature of ToM while limiting the influence of incidental task demands on results. Here, we employed the Frith-Happé animations; a silent dynamic ToM task widely used in the developmental literature, which shows reliable discrimination between children with autistic spectrum disorder and matched control groups [3, 48, 49]. Participants watch simple animations of geometric shapes moving in random, goal-directed, or in response to the mental state of each other (theory of mind) and must label the nature of the interaction (or lack of) accordingly. The advantage of this approach lies in the simplicity of the visual stimuli, contrasting with previous approaches which rely upon complex spatial arrays or detailed vignettes. This lowering of incidental task demands is important, as the cognitive loading of social cognitive tasks has been shown to adversely impact perspective-taking performance in $\mathrm{AD}[9,25,33]$.

The objectives of the present study were twofold. First, we sought to investigate the capacity for 'online' mental state attribution in well-characterized cases of bvFTD using the Frith-Happé animations, and to compare their performance with that of disease-matched AD cases. Given that no study to date has used this dynamic task in dementia syndromes, a second aim was to delineate the neural substrates of ToM performance in each patient group 
using whole-brain voxel-based morphometry analyses, to further illuminate our understanding of the social brain.

\section{MATERIALS AND METHODS}

\section{Participants}

A total of 61 participants were included in the study. Eighteen patients with a clinical diagnosis of probable $\mathrm{AD}$ with predominantly amnestic presentation were contrasted with 18 bvFTD patients presenting with socioemotional and executive dysfunction. Patient performance was compared to that of 25 cognitively intact older Controls. Participants were recruited through FRONTIER, the frontotemporal dementia research group in Sydney. Clinical diagnoses were established in accordance with current diagnostic criteria for AD [35] or bvFTD [7] by consensus among a multidisciplinary team of a senior neurologist, neuropsychologist, and occupational therapist based on detailed cognitive assessment, clinical investigation, activities of daily living, and structural neuroimaging. Disease staging was estimated in terms of duration of months elapsed since symptom onset. Functional status of patients was determined using the frontotemporal dementia Functional Rating Scale (FRS) [50], a dementia staging tool sensitive to changes in functional abilities, activities of daily living, and behavioral symptoms.

Healthy Controls were recruited from volunteer panels and local community groups. All controls scored 88 or above on the Addenbrooke's Cognitive Examination-III (ACE-III) [51] and 0 on the Clinical Dementia Rating scale (CDR) [52]. Exclusion criteria for all participants included: significant head injury, movement disorders, cerebrovascular disease, alcohol and other substance abuse, significant history of mental illness, and limited English proficiency.

Ethical approval for this study was obtained from the University of New South Wales ethics committee and the South Eastern Sydney Local Health District. All participants, or their Person Responsible, provided informed consent in accordance with the Declaration of Helsinki. Participants volunteered for their time and were reimbursed for travel costs.

\section{Behavioral tasks}

\section{General cognitive screening}

All participants completed a comprehensive battery of neuropsychological tests assessing integrity of the main cognitive domains. Global cognitive functioning was assessed using the ACE-III [51], which comprises orientation, memory, verbal fluency, language, and visuospatial subscales. Attention and working memory were measured using Digit Span forwards and backwards [53]. The Trail Making Test (Part B-A) [54] provided an index of executive function, while the Hayling Sentence completion test was included as a measure of response inhibition (Scaled Score C) [55]. Verbal episodic memory performance was measured using the Rey Auditory Verbal Learning Test (RAVLT) [56], whereas the Rey Complex Figure test was used as an index of nonverbal episodic memory (RCF) [57]. A percentage retained score was derived for RCF performance to control for executive and visuoconstructive processes (Recall score/Copy score $\times 100$ ).

\section{Behavioral and socioemotional disturbance}

Carers rated the extent of behavioral change in the patient groups via the Cambridge Behavioral Interview (CBI) [58]. In addition, a subset of carers (AD, $n=11$; and bvFTD, $n=13$ ) rated changes in socioemotional functioning in patients using the Empathic Concern (EC) and Perspective Taking (PT) subscales of the Interpersonal Reactivity Index (IRI) [59].

\section{Assessment of Theory of Mind}

Participants completed a revised version of the Frith-Happé animations task, as a dynamic assessment of 'on-line' mentalizing capacity [48]. Briefly, participants view a series of short silent animations, in which two geometric shapes (triangles) move about the screen. Three types of animations are presented: 1) Random, in which the movement of the triangles is purposeless and conveys little regarding the interaction, goals, or intentions of the triangles (e.g., bouncing); 2) Goal-Directed, in which the interaction between the two triangles depicts a clear behavioral purpose (e.g., dancing); 3) ToM, in which the interactions between the triangles suggest that one triangle anticipates or manipulates the "mental state" of the other (e.g., tricking). Examples of the test stimuli are provided at https://sites.google.com/site/ utafrith/research.

Participants were required to view each animation and to give a concurrent verbal description of what was happening (i.e., narratives). At the end of each animation, participants then selected an appropriate multiple-choice categorization: "No Interaction" (Random), "Physical Interaction" (Goal-Directed), or "Mental Interaction" (ToM). The multiple-choice 
options were clearly visible on a sheet of paper in front of participants for the duration of the task (see Supplementary Material).

Participants completed two practice trials and were given feedback to ensure they were familiar with, and understood, task requirements. Then, the 12 animations were presented one at a time in a pseudo-random order. General prompts were given to ensure participants remembered task instructions but without being directive (e.g., "Can you tell me what is happening here"). No further feedback was given. Participants could only view each animation once.

\section{Affective inference on Theory of Mind trials}

If participants correctly identified a "Mental Interaction" on ToM trials, two additional multiple-choice questions were presented. Participants were asked to select from five adjectives, which feeling best applied to each of the two triangles at the end of the animation (e.g., 'Frustrated', 'Loving', 'Tense', 'Playful', or 'No Feelings'). These questions thus provided an index of affective state inference and were not asked if participants failed to identify ToM animations, or on Random and Goal-Directed trials.

\section{Multiple choice scoring}

Correct categorization of interactions across the three experimental conditions (Random, GoalDirected, ToM) were each awarded 1 point, leading to a maximum score of 4 points per condition, and a total of 12 points overall. Correct attribution of feelings on ToM trials, were each awarded 1 point ( 2 per ToM animation), leading to a maximum score of 8 points.

\section{Coding of narrative content}

Narrative content of ToM trials was analyzed for Appropriateness and Intentionality, in line with previous studies [3, 49]. The Appropriateness score reflected participants' comprehension of the central theme of the animations, rated by the experimenter as 3 = 'appropriate descriptions', 2 = 'partially appropriate descriptions' (including descriptions that focused on one aspect or character of the script), or $1=$ 'nonappropriate descriptions' ('don't know' or unrelated answers). The Appropriateness criteria was specific to the events depicted in each animation; for example, for the animation depicting 'mocking', the narrative needed to convey the idea that the little triangle was copying the big triangle with the intention of not being noticed, e.g., 'pretending', 'hiding', 'being naughty'.
The Intentionality score captured participants' appreciation of mental states based on their use of verbs (e.g., 'floating', 'running', 'mocking'). An 'intentionality ladder' was used to rank verbs on a 6-point scale with lower levels indicating nondeliberate movement and no interaction between the agents, all the way to purposeful actions deliberately intended to affect the other agent's mental state. The highest-scoring verb within each narrative was taken as that narrative's Intentionality score. Finally, Appropriateness and Intentionality scores were averaged across ToM trials. To maximize data across participants, the average score was included provided the individual had elaborated to some degree on at least three of four ToM trials.

\section{Intentionality rating scale}

1) Non-deliberate movement and no appreciation of, or interaction with, another agent, e.g., 'moving around' 'floating'.

2) Purposeful movement with no interaction, e.g., 'walking', 'swimming'.

3) Purposeful action with another agent (parallel in time), e.g., 'fighting', 'following'.

4) Purposeful action in response to actions of another agent (sequential in time), e.g., 'copying', 'chasing'.

5) Actions in response to a mental state, e.g., 'mocking', 'arguing'.

6) Actions with the goal of affecting another agent's mental state, e.g., 'persuading', 'surprising'.

Narratives were coded by A.S. unblinded to participant group. To guard against potential bias, an independent rater (A.M.) scored a randomly selected subset of transcripts $(n=10)$ comprising Control, bvFTD, and $\mathrm{AD}$ narratives, blind to participant diagnoses and study hypotheses. Inter-rater reliability was established using the intraclass correlation coefficient. Excellent convergence was evident as revealed by Cronbach's alpha across Intentionality (Random: $\alpha=0.802$; Goal directed $\alpha=0.848$; ToM $\alpha=0.849$ ) and Appropriateness (Random $\alpha=0.811$; Goal-directed $\alpha=0.897$; ToM $\alpha=0.945$ ) subscales.

\section{Statistical analyses}

Behavioral data were analyzed using IBM SPSS Statistics (Version 23). Univariate analyses of variance (ANOVA) investigated main effects of group (AD, bvFTD, Controls) across demographic 
variables and background neuropsychological tests, with the exception of sex, for which a Chi-square test $\left(\chi^{2}\right)$ was used. Given the low range of possible scores on the experimental task, non-parametric tests were employed. Kruskal-Wallis tests $(\mathrm{H})$ were used to investigate main effects of group for the multiple-choice categorization scores, as well as the Appropriateness and Intentionality content scores for ToM narratives. Simple effects were then explored using Mann-Whitney tests (U), with Šidák correction for multiple comparisons. Within-subject differences across conditions were explored using Friedman tests followed by Wilcoxon post-hoc tests, with Šidák correction for multiple comparisons. Finally, onetailed Spearman rank correlations were conducted to explore within-group relationships between task performance and cognitive domains of interest. Statistical significance was set at $p<0.05$, with the exception of the correlation analyses where a more stringent $p<0.01$ was employed to guard against the potential for false positive findings. Effect sizes are reported using eta-squared $\left(\eta^{2}\right)$ for parametric, and $\mathrm{r}$ coefficients for non-parametric, analyses.

\section{MRI acquisition}

Participants underwent whole-brain imaging using a 3T Philips MRI scanner with standard quadrature head coil (eight channels). Structural $\mathrm{T}_{1}$-weighted images were acquired via the following sequences: coronal orientation, matrix $256 \times 256,200$ slices, 1 $\mathrm{mm}^{2}$ in-plane resolution, slice thickness $1 \mathrm{~mm}$, echo time $/$ repetition time $=2.6 / 5.8 \mathrm{~ms}$, flip angle $\alpha=8^{\circ}$. Scans were examined by a neuroradiologist for structural abnormalities; none were reported for Controls. Prior to analyses, all scans were visually inspected for significant head motion artefacts. Scans were available for $16 \mathrm{AD}, 13 \mathrm{bvFTD}$, and 24 Control participants.

\section{Voxel-Based Morphometry (VBM)}

Structural MRI data were analyzed using the FSL-VBM toolbox $[60,61]$ from the FMRIB software package [62] (http://www.fmrib.ox.ac.uk/fsl/ fslvbm). Briefly, images were extracted using the FSL brain extraction tool [63], following which tissue segmentation was conducted using FMRIB's Automatic Segmentation Tool [64]. Grey matter partial volumes were aligned to the Montreal Neurological standard space (MNI152) via the FMRIB non-linear registration technique $[65,66]$ using a $b$-spline representation of the registration warp field [67]. A study-specific template was created in which $\mathrm{AD}$, bvFTD, and Control participants were equally represented, following which the native grey matter images were re-registered non-linearly to this template. The registered partial volume maps were then modulated by dividing by the Jacobian of the warp field to correct for local expansion or contraction. Modulated segmented images were smoothed using an isotropic Gaussian kernel with a sigma of $3 \mathrm{~mm}$.

\section{Covariate analyses}

Correlations between performance on the experimental task and regions of grey matter atrophy were explored in each patient group combined with Controls, by including the total multiple-choice categorization score as a covariate in the general linear model. The total multiple-choice score was included as the covariate of interest given its larger range of possible scores (0-12) ensuring sufficient variability in the data to capture brain-behavior relationships. For statistical power, a covariate only statistical model with a positive [1] t-contrast was used, providing an index of association between grey matter intensity and performance on the experimental task. Education was included as a nuisance variable in these analyses. Clusters were extracted voxelwise and reported uncorrected at $p<0.001$, using a conservative cluster extent threshold of 100 contiguous voxels. This approach minimizes Type I error whilst balancing the risk of Type II error [68] and is consistent with previously published methods $[69,70]$.

Anatomical locations of significant results were overlaid on the MNI standard brain, with maximum coordinates provided in MNI stereotaxic space. Anatomical labels were determined with reference to the Harvard-Oxford probabilistic cortical atlas.

\section{RESULTS}

\section{Demographics and clinical characteristics}

Table 1 displays background clinical and cognitive data. The groups did not differ in terms of age $(F(2,58)=2.861, p=0.065)$ or sex distribution $\left(\chi^{2}=3.963, p=0.057\right)$. Education, however, differed between the groups $(F(2,58)=6.800, p=0.002)$, with Controls spending significantly longer in formal education relative to $\mathrm{AD}(p=0.007)$ and bvFTD $(p=0.011)$ patients (AD versus bvFTD; $p=0.998)$. Patient groups did not differ in terms of disease 
Table 1

Demographic and neuropsychological performance of the study cohort ${ }^{\mathrm{a}, \mathrm{b}}$

\begin{tabular}{|c|c|c|c|c|c|}
\hline Demographics \& cognitive tests & $\mathrm{AD}(n=18)$ & bvFTD $(n=18)$ & Control $(n=25)$ & F test & Post hoc \\
\hline Age (y) & $68.9(8.2)$ & $63.1(8.8)$ & $66.8(5.5)$ & n.s. & - \\
\hline Education (y) & $11.8(2.9)$ & $11.9(2.6)$ & $14.2(2.2)$ & $* *$ & Patients $<$ Controls \\
\hline Sex M:F & $10: 8$ & $14: 4$ & $12: 13$ & n.s. & - \\
\hline Disease Duration (y) & $6.3(4.4)$ & $6.25(3.5)$ & - & n.s. & - \\
\hline FRS (Rasch score) & $0.87(1.3)$ & $-1.08(1.4)$ & - & $* * *$ & AD > bvFTD \\
\hline CBI memory (\%) & $54.2(15.2)$ & $46.4(27.4)$ & $7.2(5.6)$ & $* * *$ & Patients $>$ Controls \\
\hline CBI abnormal behavior (\%) & $13.9(14.6)$ & $38.9(24.7)$ & $1.5(2.8)$ & $* * *$ & AD, Controls $<$ bvFTD \\
\hline ACE-III Total (100) & $68.4(10.4)$ & $75.8(11.7)$ & $95.5(6.8)$ & $* * *$ & $\mathrm{AD}<$ bvFTD $<$ Controls \\
\hline Digit Span Forward (Raw Total) & $8.3(1.6)$ & $8.9(1.9)$ & $11.7(2.1)$ & $* * *$ & Patients $<$ Controls \\
\hline Digit Span Backward (Raw Total) & $4.4(2.0)$ & $4.7(1.9)$ & $7.6(2.6)$ & $* * *$ & Patients $<$ Controls \\
\hline Hayling Scaled Score C & $4.3(2.3)$ & $3.4(2.7)$ & $6.8(1.7)$ & $* * *$ & Patients $<$ Controls \\
\hline ACE-III Fluency & $8.1(1.2)$ & $7.6(3.9)$ & $12.6(1.2)$ & $* * *$ & Patients $<$ Controls \\
\hline RAVLT immediate recall (15) & $2.25(1.9)$ & $4.77(3.0)$ & $10.6(2.7)$ & $* * *$ & $\mathrm{AD}<$ bvFTD $<$ Controls \\
\hline RAVLT delayed recall (15) & $1.4(1.3)$ & $5.2(3.0)$ & $10.7(3.2)$ & $* * *$ & Controls $>$ bvFTD $>$ AD \\
\hline RCF copy (36) & $23.2(11.5)$ & $26.9(7.2)$ & $32.9(2.7)$ & $* * *$ & Patients $<$ Controls \\
\hline RCF 3 minute recall (36) & $3.0(4.4)$ & $10.2(6.2)$ & $16.9(5.2)$ & $* * *$ & $\mathrm{AD}<$ bvFTD $<$ Controls \\
\hline $\mathrm{RCF} \%$ retained & $13.2(13.5)$ & $37.8(21.4)$ & $51.3(15.0)$ & $* * *$ & $\mathrm{AD}<$ bvFTD $<$ Controls \\
\hline Trail Making Test Part A (s) & $95.8(132.8)$ & $61.4(40.1)$ & $30.9(7.1)$ & $*$ & $\mathrm{AD}>$ Controls \\
\hline Trail Making Test Part B-A (s) & $143.3(133.2)$ & $93.7(86.8)$ & $43.1(20.3)$ & $* *$ & AD $>$ Controls \\
\hline IRI Perspective Taking $(\%)^{\mathrm{c}}$ & $48.0(14.6)$ & $41.5(11.5)$ & $73.5(10.9)$ & $* * *$ & Patients $<$ Controls \\
\hline IRI Empathic Concern $(\%)^{\mathrm{c}}$ & $66.5(19.5)$ & $56.3(21.4)$ & $82.7(9.1)$ & $* * *$ & Patients $<$ Controls \\
\hline
\end{tabular}

${ }^{a}$ Scores depict mean values with standard deviations provided in parentheses. ${ }^{b}$ Maximum test scores provided in parentheses, where appli-

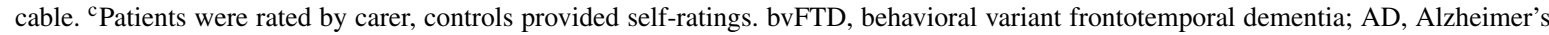
disease; FRS, Frontotemporal Dementia Rating Scale; ACE-III, Addenbrooke's Cognitive Examination - 3rd Edition; CBI, Cambridge Behavioral Inventory; RCF, Rey Complex Figure test; RAVLT, Rey Auditory Verbal Learning Test; IRI, Interpersonal Reactivity Index. Unavailable data by test and group: CBI, 5 controls; ACE-III and ACE-III Fluency, 1 bvFTD; Digit span, 2 AD and 1 controls; Hayling Scaled score C, 9 AD, 2 bvFTD, and 2 controls; RAVLT short delay and long delay, 2 AD, 5 bvFTD, and 1 controls; RAVLT recognition, 3 $\mathrm{AD}, 5$ bvFTD, and 1 controls; RCF copy, $3 \mathrm{AD}$ and 2 bvFTD; RCF three minute recall and \% retained, 4 AD and 2 bvFTD; Trail Making Test part A, 2 AD, and 2 controls; Trail Making Test part B and B-A, 6 AD, 6 bvFTD and 2 controls; IRI perspective taking and empathic concern, $7 \mathrm{AD}, 5$ bvFTD, and 7 controls. *p<0.05; **p<0.01; ***p<0.001; n.s. not significant; '-', not applicable.

duration (months elapsed since onset of symptoms; $p=0.995)$. While greater functional impairment was evident in bvFTD compared to AD (FRS: $F(1,34)=19.031, p<0.001)$, AD patients displayed greater overall cognitive impairment relative to the bvFTD group $(p=0.041)$. These profiles are consistent with previous reports in the literature $[9,71]$.

\section{General cognitive functioning}

Patients displayed cognitive profiles in keeping with their clinical diagnoses (Table 1). Briefly, AD patients exhibited hallmark episodic memory deficits (RCF; RAVLT; CBI Memory \%), with further impairments evident in visuoconstruction (RCF Copy), processing speed (Trail Making Test A) and set-shifting (Trail Making Test B-A) relative to Controls (all $p$ values $<0.05$ ). BvFTD patients displayed characteristic impairments in attention (Digit Span Forwards), working memory (Digit Span Backwards), and delayed episodic recall (RAVLT) compared to Controls (all $p$ values $<0.001$ ).

Direct comparison of the patient groups revealed disproportionate impairments in verbal and non- verbal memory in AD versus bvFTD (RCF; RAVLT; both $p$ values $<0.01$ ). In contrast, carers of bvFTD patients reported higher levels of abnormal behaviors on the CBI (e.g., tactless, impulsive, embarrassing, or uncooperative behavior) relative to the $\mathrm{AD}$ group $(p<0.001)$.

\section{Socioemotional functioning}

Carer ratings on the IRI revealed lower capacity for empathy in both patient groups relative to controls. Perspective Taking (i.e., cognitive empathy) was significantly disrupted in AD and bvFTD ( $p$ values $<0.001$ ), as was Empathic Concern (i.e., affective empathy; AD, $p=0.043$; bvFTD, $p<0.001$ ). No significant differences were observed between the patient groups for either subscale on the IRI (Perspective Taking: $p=0.484$; Empathic Concern: $p=0.362$ ).

\section{Theory of mind performance}

\section{Overall classification of interactions}

A Kruskal-Wallis test revealed a significant main effect of group for the correct classification 
of trials $(\mathrm{H}(2)=17.769, \quad p<0.001)$. Follow-up Mann-Whitney $U$ tests revealed that, irrespective of condition, both $\mathrm{AD}(U=77.50, Z=-3.67, p<0.001$, $r=-0.56)$ and bvFTD $(U=77.50, \quad Z=-1.73$, $p=0.001, r=-0.51)$ patients showed poorer categorization of the animated trials relative to Controls, with no significant differences between the patient groups $(U=138.0, Z=-0.77, p=0.462, r=-0.13)$.

\section{Classification performance by interaction type}

Figure 1 displays the classification of animations by interaction type across participant groups. A significant main effect of group was observed in the Random condition, $(\mathrm{H}(2)=11.798, p=0.003)$, driven exclusively by poor performance in the $\mathrm{AD}$ group relative to Controls $(U=98.5, p=0.001, Z=-3.409$, $r=-0.52)$. In contrast, bvFTD patients scored in line with Controls by correctly classifying random movements $(U=165.500, p=0.084, Z=-1.730$, $r=-0.26)$. No significant differences were evident between the patient groups $(U=111.500, p=0.096$, $Z=-1.665, r=-0.28)$.

No main effect was observed on Goal-Directed trials, $(\mathrm{H}(2)=1.090, p=0.580)$, indicating that patients could correctly classify the purposeful and concrete physical interactions of the animated triangles (e.g., playing tennis).

Finally, a main effect of group was observed $(\mathrm{H}(2)=15.954, p<0.001)$ in the ToM condition, with significant impairments emerging in both patient groups compared to Controls (AD, $U=118.0$, $p=0.004, Z=-2.892, r=-0.44$; bvFTD,$U=76.0$, $p<0.001, Z=-3.935, \quad r=-0.60)$. No significant

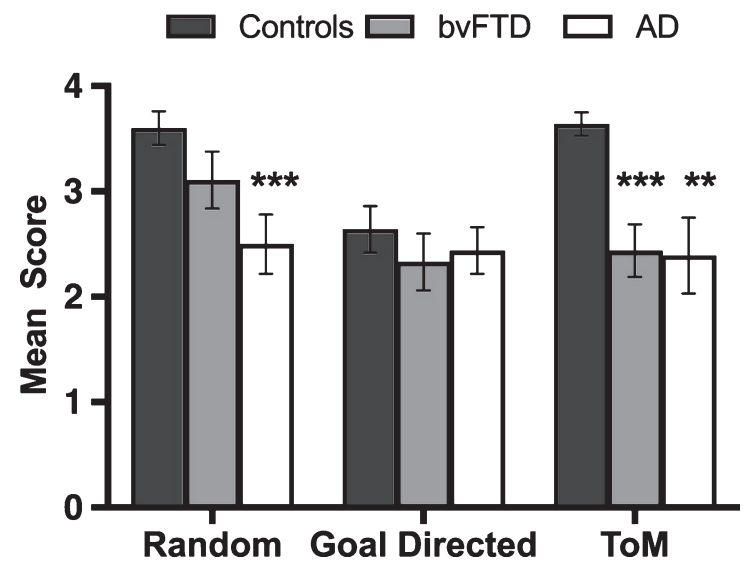

Fig. 1. Mean correctly identified animated shapes trials by trial type and group. Error bars display standard error of the mean. Asterisks denote group differences relative to Controls: $* * p \leq 0.01 ; * * * p \leq 0.001$. differences were found between the patient groups $(U=157.00, p=0.888, Z=-0.163, r=-0.03)$.

Within-group comparisons using Friedman's tests in each group separately, revealed a main effect of condition in Controls $\left(\chi^{2}(2, n=25)=19.279\right.$, $p<0.001$ ), with significantly poorer performance on Goal-Directed relative to Random $(z=-3.363$, $p=0.001, r=-0.67)$ and ToM $(z=-3.020, p=0.003$, $r=-0.60)$ trials. In contrast, performance was comparable across conditions for $\operatorname{AD}\left(\chi^{2}(2, n=18)=0.918\right.$, $p=0.632)$ and bvFTD $\left(\chi^{2}(2, \quad n=18)=3.966\right.$, $p=0.138$ ) patients.

\section{Identification of feelings on ToM trials}

Given that the 'feelings' questions related exclusively to correctly classified ToM trials, a reduced pool of responses was available across participant groups (Controls 91.0\%, AD 59.7\%, bvFTD $61.1 \%$ of available questions). Figure 2 displays average correct responses for feelings identification on correctly classified ToM trials. A significant main effect of group was observed for accuracy on the identification of ToM Feelings $(\mathrm{H}(2)=28.906$, $p<0.001)$, reflecting the poorer performance of both $\operatorname{AD}(U=35.500, Z=-4.297, p<0.001, r=-0.68)$ and bvFTD $(U=34.0, Z=-4.614 p=<0.001, r=-0.71)$ patients, relative to Controls. No significant differences were observed between the patient groups $(U=114.5, Z=-0.502, p=0.628, r=0.09)$.

\section{Correlations}

One-tailed Spearman correlations explored associations between classification of interactions on ToM

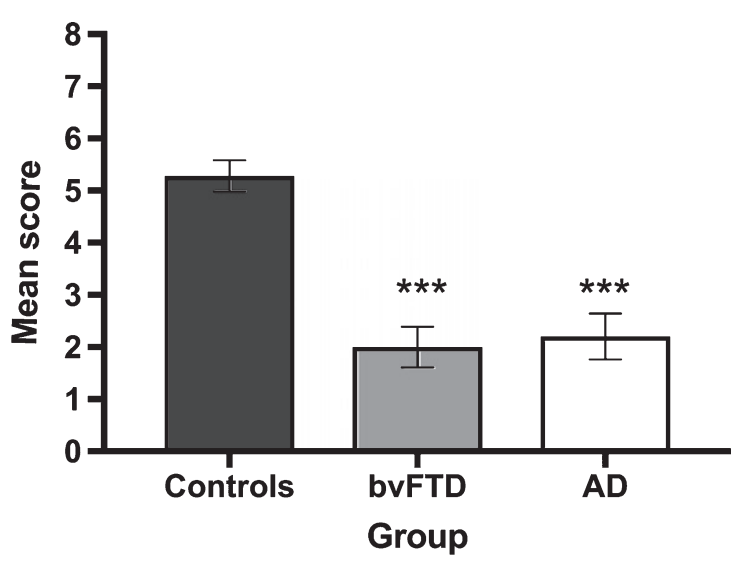

Fig. 2. Mean performance for the correct identification of feelings on Theory of Mind trials by group. Error bars display standard error of the mean. Asterisks denote group differences relative to Controls: $* * * p \leq 0.001$. 
Table 2

Correlations between classification of ToM trials and cognitive and interpersonal variables by group ${ }^{\mathrm{a}}$

\begin{tabular}{lccc}
\hline & Controls & AD & bvFTD \\
\hline ACE-III & 0.161 & 0.353 & -0.300 \\
Digit Span (F) & 0.089 & 0.060 & -0.079 \\
ACE-III Fluency & 0.289 & 0.342 & -0.086 \\
RAVLT Immediate Recall & 0.357 & $\mathbf{0 . 5 8 8} * *$ & 0.074 \\
Trail Making Test (A) & -0.089 & -0.236 & -0.074 \\
Trail Making Test (B-A) & 0.300 & 0.018 & 0.026 \\
Hayling Scaled Score (C) & 0.339 & -0.155 & 0.038 \\
RCF Copy & 0.208 & -0.239 & 0.297 \\
CBI Total & -0.129 & -0.281 & -0.222 \\
IRI-EC & -0.187 & 0.250 & $\mathbf{0 . 7 1 2} * *$ \\
IRI-PT & -0.079 & 0.213 & -0.327
\end{tabular}

** $p \leq 0.01$. ${ }^{\text {a }}$ Unavailable data by test and group: ACE-III and ACE-III Fluency, 1 bvFTD; Digit Span, 1 control and 2 AD; RAVLT Short Delay, 1 control, 2 AD, and 5 bvFTD; Trails A, 2 controls and $2 \mathrm{AD}$; Trails B-A, 2 controls, $6 \mathrm{AD}$, and 6 bvFTD; Hayling Scaled score C, 9 AD, 2 bvFTD, and 2 controls; RCF copy, $3 \mathrm{AD}$ and 2 bvFTD; CBI Total, 5 controls; IRI-EC and IRI-PT, 7 controls, $7 \mathrm{AD}$, and 5 bvFTD.

trials and cognitive domains of interest in each participant group separately (Table 2). A significant positive association was observed between verbal episodic memory and correct categorization of ToM trials in $\mathrm{AD}(r=0.588)$. In contrast, carer ratings of empathic concern on the IRI correlated with ToM performance in bvFTD $(r=0.712)$. No other significant associations were evident at the corrected threshold of $p<0.01$.

\section{ToM narrative descriptions}

Constraining our focus to ToM trials, participants' accompanying narratives were analyzed in terms of Appropriateness (i.e., accurate description of the activities portrayed in the animation) and Intentionality (i.e., the use of verbs reflecting the appreciation of mental states) (see Fig. 3). Representative transcripts are included in Supplementary Material.

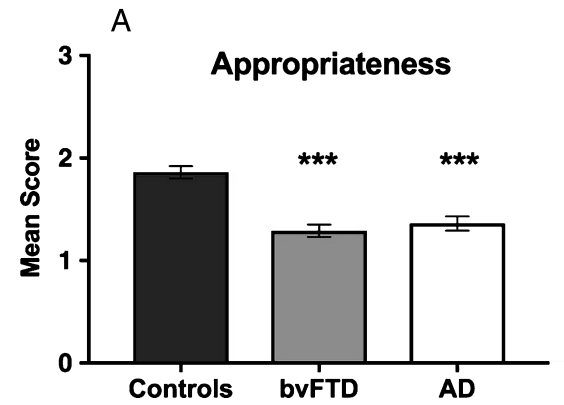

Appropriateness

A significant main effect of group was observed for Appropriateness $(\mathrm{H}(2)=28.350, p<0.001)$, reflecting the fact that both $\mathrm{AD}(U=57.000, Z=-4.222$, $p<0.001, r=0.64)$ and bvFTD $(U=40.0, Z=-4.634$, $p<0.001, r=0.71)$ patients gave less accurate descriptions of the activities portrayed by the shapes compared to Controls. AD and bvFTD groups did not differ in Appropriateness $(U=140.5, Z=-0.726$, $p=0.468, r=-0.12$ ).

\section{Intentionality}

A significant main effect of group was also observed for Intentionality $(\mathrm{H}(2)=13.474$, $p=0.001)$, reflecting compromised mental state attributions in both the $\mathrm{AD}(U=121.0, Z=-2.595$, $p=0.009, \quad r=0.40)$ and bvFTD $(U=94.000$, $Z=-3.268, p=0.001, r=0.50)$ groups relative to Controls. No significant differences were observed between the patient groups for Intentionality $(U=$ 117.500, $Z=-1.443, p=0.149, r=-0.24)$.

\section{Controlling for verbal generativity}

During scoring, it was noted that patients generated less verbal content overall than Controls. To control for generativity, a word count was performed on, and averaged across, the ToM trials. Audio recordings were not available for 2 Controls, 2 ADs, and 2 bvFTD participants. In these cases, the missing value for each participant was imputed using mean substitution.

An analysis of covariance (ANCOVA), with word count as a covariate, continued to reveal main effects of group for Appropriateness $(\mathrm{F}(2$, $\left.57)=8.176, p=0.001, \eta^{2}=0.19\right)$ and Intentionality $\left(\mathrm{F}(2,57)=4.114, p=0.021, \eta^{2}=0.12\right)$. Post hoc simple effects analyses, however, revealed an altered pattern of findings. That is, controlling for word count served to ameliorate the deficits in the $\mathrm{AD}$

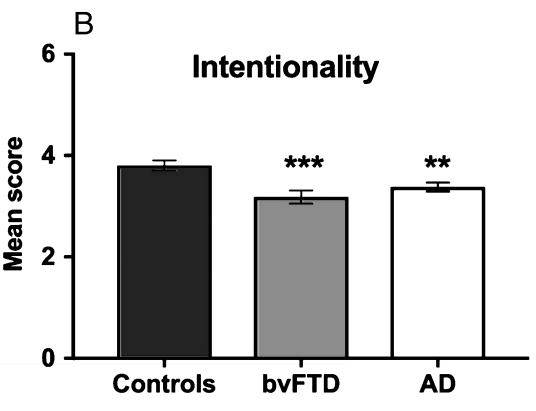

Fig. 3. Breakdown of narrative content on Theory of Mind trials in terms of (A) Appropriateness and (B) Intentionality across participant groups. Error bars display the standard error of the mean. Asterisks denote group differences relative to Controls: $*^{*} p \leq 0.01 ; * * * p \leq 0.001$. 
group relative to Controls, including how well they captured the intended underlying script (Appropriateness, $p=0.087$ ) and their appreciation of mental states (Intentionality, $p=0.528$ ). In contrast, the bvFTD group continued to show significant deficits relative to Controls for Appropriateness $(p<0.001)$ and Intentionality $(p=0.020)$.

\section{Neural correlates of task performance}

Figure 4 shows the significant regions to emerge from the covariate analyses investigating overall task performance (i.e., correct classification of interactions across conditions) in AD and bvFTD, controlling for education.

In $\mathrm{AD}$, overall classification performance correlated with integrity of the right hippocampus, and lobules I-IV and V of the cerebellum, bilaterally. In contrast, a distributed network of regions was implicated in the bvFTD group, including the bilateral medial, orbitofrontal, and frontoinsular cortices, and the caudate. Left lateral anterior temporal regions further emerged as significant in the analyses, as did regions in the left lateral parietal cortex, and the precuneus, bilaterally. Finally, subregions of the cerebellum including the bilateral lobules I-IV and V, Right Crus I and Crus II, and left lobule VI were also implicated (Table 3).

\section{DISCUSSION}

This study demonstrates comparable deficits in the classification of ToM interactions and feelings in

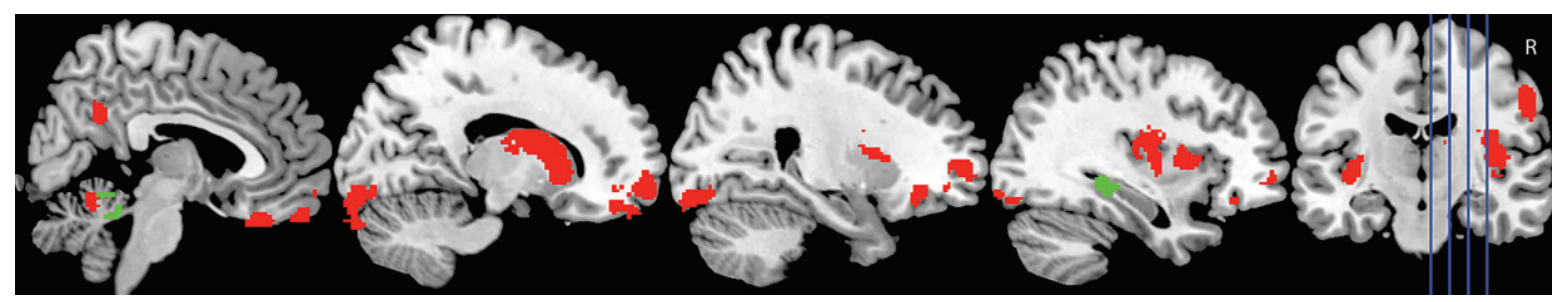

Fig. 4. Voxel-based morphometry covariate analyses showing brain regions which correlate significantly with task performance in AD (green) and bvFTD (red). Colored voxels show regions that were significant in the analyses at $p<0.001$ uncorrected. All clusters reported $t>3.3$. Education is included as a covariate in all analyses. R, right. For full description of clusters and relevant coordinates, please refer to Table 3.

Table 3

Voxel-based morphometry results showing regions of significant grey matter intensity decrease associated with classification of interactions in $\mathrm{AD}$ and bvFTD, combined with Controls

\begin{tabular}{|c|c|c|c|c|c|c|}
\hline \multirow[t]{2}{*}{ Contrast } & \multirow[t]{2}{*}{ Regions } & \multirow[t]{2}{*}{ Side } & \multirow{2}{*}{$\begin{array}{c}\text { Number of } \\
\text { voxels }\end{array}$} & \multicolumn{3}{|c|}{ MNI coordinates } \\
\hline & & & & $x$ & $y$ & $z$ \\
\hline \multirow[t]{2}{*}{$\mathrm{AD}$} & Cerebellum, lobules I-IV and V & B & 313 & -10 & -42 & -32 \\
\hline & Hippocampus & $\mathrm{R}$ & 137 & 30 & -26 & -14 \\
\hline \multirow[t]{15}{*}{ bvFTD } & Accumbens, caudate, insular cortex & $\mathrm{R}$ & 1,390 & 12 & 12 & -6 \\
\hline & Medial prefrontal cortex, orbitofrontal cortex, frontal pole & $\mathrm{R}$ & 812 & 4 & 26 & -28 \\
\hline & Cerebellum, Crus I extending into right lobules I-IV, V, and Crus II & $\mathrm{R}$ & 715 & 54 & -66 & -38 \\
\hline & Insular cortex, central opercular cortex & $\mathrm{L}$ & 464 & -36 & -10 & -14 \\
\hline & Medial prefrontal cortex, orbitofrontal cortex, frontal pole & $\mathrm{L}$ & 462 & -6 & 30 & -28 \\
\hline & Temporal fusiform cortex (anterior), temporal pole & $\mathrm{L}$ & 329 & -32 & -6 & -38 \\
\hline & Cerebellum, lobule VI extending into left lobules I-IV and V & $\mathrm{L}$ & 310 & -10 & -64 & -26 \\
\hline & Occipital fusiform gyrus, occipital pole & $\mathrm{L}$ & 284 & -18 & -88 & -14 \\
\hline & Postcentral gyrus & $\mathrm{R}$ & 250 & 58 & -16 & 28 \\
\hline & Precuneus cortex & $\mathrm{B}$ & 205 & 2 & -54 & 24 \\
\hline & Orbitofrontal cortex, putamen, caudate & $\mathrm{L}$ & 186 & -26 & 22 & -16 \\
\hline & Frontal pole & $\mathrm{L}$ & 184 & -16 & 56 & -22 \\
\hline & Orbitofrontal cortex, frontal pole & $\mathrm{R}$ & 135 & 42 & 32 & -20 \\
\hline & Superior parietal lobule & $\mathrm{L}$ & 112 & -34 & -38 & 52 \\
\hline & Middle temporal gyrus (temporooccipital), angular gyrus & $\mathrm{R}$ & 107 & 44 & -44 & 8 \\
\hline
\end{tabular}

MRI scans not available for $2 \mathrm{AD}, 5$ bvFTD, and 1 Control participant. All clusters reported using voxel-wise contrasts, uncorrected at $p<0.001$, and with a cluster extent threshold of 100 contiguous voxels. Years in education included as a nuisance variable in all contrasts. All clusters reported at $t>3.3$. L, left; R, right; B, bilateral; MNI, Montreal Neurological Institute. 
bvFTD and AD, using the Frith-Happé animations. Whereas ToM disruption in AD appears to be primarily mediated by hippocampal degeneration, ToM impairments in bvFTD reflect the breakdown of a distributed set of regions implicated in specific social and affective cognitive processes. We discuss our findings in terms of understanding different drivers of theory of mind disruption across dementia syndromes, and how damage to discrete brain regions impacts the capacity for social inference.

The most striking finding to emerge from our study was the observation of marked impairments in mental state attribution in bvFTD on a simplified task designed to minimize cognitive load. Critically, these impairments were not attributable to a broader difficulty in comprehending ambiguous movements or interactions more generally, as bvFTD patients scored in line with Controls for Random and Goaldirected classification. Moreover, this mentalizing deficit spanned both cognitive and affective branches of ToM, as even when bvFTD patients successfully determined that a ToM interaction had taken place, they could not accurately identify the predominant feelings of the main characters. Our findings thus reinforce a large body of evidence pointing to bvFTD as a disorder of social cognition, with marked deficits evident irrespective of ToM domain, or indeed the cognitive loading of the task $[9,20,38,72]$.

Correlation analyses did not show significant associations between overall task performance, and neuropsychological tests of executive function, episodic memory, or semantic comprehension in bvFTD. This lack of association between ToM performance and executive function is in contrast with the proposal of a domain-general executive component to mental state attributions [21, 73] and may reflect the limited nature of our executive battery (Digit span, Trail Making Test, Hayling Test). The relationship between executive dysfunction and ToM disruption in bvFTD remains poorly understood [74], and depends upon the nature of the ToM and executive tasks employed, and the disease severity of the patient samples [22]. In this context, the only significant association to emerge was with carer ratings of empathic concern on the Interpersonal Reactivity Index, a measure of the capacity to share the feelings of others. While our findings reinforce the close correspondence between ToM dysfunction and the characteristic loss of empathy displayed in everyday social interactions in bvFTD [75], the cognitive mechanisms underlying these symptoms remain unclear.
Turning our attention to the AD group, significant impairments were evident not only for ToM attributions, but also for Random movement classifications. Interestingly, $\mathrm{AD}$ patients scored in line with Controls for Goal-Directed trials, in which the triangles moved purposefully in a concrete pattern. This profile of responses may therefore reflect an inability to build a figurative interpretation from ambiguous movements, reflecting the general deterioration in abstract reasoning commonly observed in AD [76]. Overall task performance was found to correlate with episodic immediate recall on the RAVLT, suggesting that the short delay between viewing the animations and subsequently conferring a judgment may have further impacted $\mathrm{AD}$ performance. While we did not directly assess response times, it was noted during testing that participants tended to provide their classification response whilst viewing Goal-Directed trials, whereas for Random and ToM conditions, participants tended to wait until the events of the animation had unfolded before responding. Similarly, judgments of affective ToM were as impaired in AD as bvFTD, with some AD patients commenting that they simply could not remember what had transpired during the animation in order to answer the affective questions. Concordant with recent findings [36], we suggest that the ToM deficit in AD is multifactorial, in this case, reflecting difficulties in interpreting the ambiguous nature of the stimuli, coupled with hallmark impairments in episodic memory.

Analysis of participants' narratives provided further insights into the nature of the ToM impairment in bvFTD and AD. Both patient groups showed comparable difficulties in conveying an accurate description of the animations (Appropriateness) and the use of suitable verbs to reflect the underlying mental state (Intentionality). Importantly, this on-line capacity to interpret the animations as they unfold in real time is proposed to reflect the fast-paced nature of social interactions, lending ecological validity to the task [48]. Nevertheless, the production of verbal narratives in this manner is highly dependent on generative processes, known to be impacted in both syndromes [77]. Controlling for the overall production of content during narration served to ameliorate the Appropriateness and Intentionality deficits in the $\mathrm{AD}$, but not the bvFTD, group. This finding suggests that the relative paucity of verbal material generated by $\mathrm{AD}$ patients may, at least partially, underlie the diminished quality of their narrative descriptions. In contrast, deficits across both tasks persisted 
in the bvFTD group, despite controlling for verbal production.

VBM analyses allowed us to further explore the potential mechanisms driving ToM impairments in each patient group. In keeping with previous studies, we demonstrated robust associations between task performance in bvFTD and atrophy in a distributed set of brain regions, including bilateral medial and orbitofrontal, frontopolar, insular, lateral temporal, and occipitoparietal cortices. These regions have previously been implicated in cognitive perspectivetaking deficits in bvFTD [9] suggestive of a common neural mechanism mediating cognitive aspects of social inference. Moreover, activity in this network is consistently reported in functional neuroimaging studies of ToM [78] and increases disproportionately with mentalizing level [79]. It is important to note that many of the regions implicated in ToM dysfunction in bvFTD are critical nodes of the brain's 'Salience Network'; a distributed functional network posited to play a central role in processing socially salient internal and external stimuli [80]. Degeneration of the Salience Network has been proposed to underlie the florid socioemotional difficulties characteristic of bvFTD, limiting the capacity to rapidly process, integrate, and respond to socially-relevant information [81, 82].

In addition, we found that task performance in bvFTD was associated with atrophy in dorsal (caudate nucleus, putamen) and ventral (nucleus accumbens) striatal regions, which have previously been implicated in cognitive and affective aspects of ToM attribution, respectively [83]. Striatal contributions to ToM are seldom discussed, although a number of studies have documented striatal activity during mentalizing tasks [83, 84]. Given its dense connections with cognitive, motor, and limbic circuits in the brain, striatal activity on ToM tasks may reflect the coordination of cortical and subcortical information [85] in the service of goal-directed behavior [86]. Given that fronto-striatal atrophy is disproportionately present in bvFTD compared to AD [87], it will be important for future studies to determine the precise role of the striatum in higher-order social cognitive processes.

Overall classification performance in $\mathrm{AD}$ was found to relate exclusively to grey matter intensity decrease in the right hippocampus and the cerebellum, bilaterally. Observation of a significant hippocampal contribution complements our behavioral findings, implicating episodic memory disruption as a key driver of ToM disruption in
AD. While not typically associated with ToM capacity, the hippocampal declarative memory system is proposed to support a number of processing features which may be crucial for social cognition [88]. First, the hippocampus supports representational flexibility, enabling memories to be accessed across different processing systems in the service of diverse cognitive capacities [88]. Second, the hippocampus supports on-line processing of complex configurations, enabling information to be held "inmind" in the service of task performance $[89,90]$. Patients with damage to the hippocampus display stark alterations in socioemotional functioning [88, 91], attributable to the breakdown of representational flexibility and on-line processing [88]. In the context of the current study, we suggest that disruption to these hippocampal dependent processes in $\mathrm{AD}$ impedes the ability to recognize the shifting and changing status of unpredictable trials (Random, $\mathrm{ToM})$ and to communicate the unfolding of events in a coherent manner.

Finally, an interesting, and somewhat unexpected finding, was our observation of significant cerebellar contributions to overall task performance. The common cerebellar subregions implicated, irrespective of patient group, included lobules I-IV and V, bilaterally. While not typically associated with mentalizing, the cerebellum has been implicated previously in fMRI studies of higher-order intentionality [79], basic ToM processing [92, 93], and the emergence of mentalizing deficits in neurodevelopmental disorders such as autism spectrum disorder [94]. Importantly, a recent meta-analysis of cerebellar activation in social cognitive tasks suggests that its contribution may be crucial for mentalizing in conditions where the level of abstraction is high [92]. Such abstract judgments are essential for successful social interactions, and require us to move away from the concrete "here and now" to consider abstract personality traits, hypothetical scenarios, or social group characteristics [92]. Further, a recent study suggests that the cerebellum's involvement in higher-order intentionality reasoning may reflect its coordination of multiple cognitive processes particularly when it is necessary to keep track of and differentiate between several mental states simultaneously [79]. By this view, keeping track of the states of mind of the two triangles, under highly abstract conditions, is likely to disproportionately tax the cerebellum. Notably, our finding of common anterior lobe involvement in higher-level cognitive functions resonates with previous studies [95, 96] and challenges the prevalent anterior-sensorimotor 
versus posterior-cognitive/emotional dichotomy in the human cerebellum [97].

A number of methodological issues warrant consideration in this context. First, our sample sizes are relatively modest, reducing our power to detect significant brain-behavior relationships using conservative correction methods. Accordingly, it will be important for future studies to replicate these findings in a larger sample of patients. The Frith-Happé animations present a novel way to assess the on-line interactions between agents, stripped of various semantic, executive, and attentional demands. This inherent simplicity, however, comes at a cost in terms of the ecological validity of the task in the sense that it removes much of the necessary contextual information on which social functioning is predicated. As such, paring the task back to focus on the movements of the triangles strips these animations of the naturalistic social cues that we invariably rely on to make social judgments and inferences in our daily lives. Further, although not originally intended for this purpose, the task failed to distinguish between $\mathrm{AD}$ and bvFTD patient groups across any of the ToM subscales, limiting its clinical utility in the differential diagnosis of dementia syndromes. While we did not find evidence of an association between the ToM task and visuospatial functioning, it is possible that the demands placed on shape and movement perception may impede task performance in advanced stages of $\mathrm{AD}$, and this represents an important consideration for future studies. Further, the simplicity of the triangle stimuli may, paradoxically, prove too abstract for dementia patients to conceptualize as social agents, in the face of increasingly concrete styles of thinking. Finally, a clear limitation of this task lies in the fact that, by its nature, participants are reduced to spectators rather than active participants in the social scenarios. This aspect of the task is divorced from the complex way in which we fluidly interact in social scenarios and comes at a critical cost in terms of the ecological validity of the task. The challenge for future studies will therefore be to develop ecologically valid tasks that, on the one hand, foster the active participation of individuals within the test scenario, yet at the same time ensure that cognitive demands are minimized, in order to dissociate between cognitive and affective contributions to social dysfunction. Further, as neurodegenerative disorders are characterized by widespread network disturbances [17, 81, 98], it will be crucial for future work to elucidate how alterations in structural and functional connectivity differentially impact ToM capacity across dementia syndromes.

\section{Conclusions}

In summary, we have demonstrated the pervasive nature of ToM deficits in bvFTD, manifesting across cognitive and affective domains even when a relatively simple task is employed. These deficits are attributable to the vulnerability of a distributed brain network, consistently implicated in social cognitive function. In contrast, while $\mathrm{AD}$ patients display ToM impairment of the same magnitude as observed in bvFTD, these deficits appear largely cognitively driven. A novel finding to emerge from this study was the common involvement of the cerebellum in task performance irrespective of patient group. Given mounting evidence of selective vulnerability of the cerebellum across a broad range of psychiatric [99] and neurodegenerative disorders [95], delineating the specific contribution of the cerebellum to social cognitive function represents a major challenge in dementia research.

\section{ACKNOWLEDGMENTS}

The authors are grateful to the patients and their families for their continued support of our research. The authors wish to acknowledge Jody Kamminga and Nadene Dermody for their assistance with participant recruitment and testing. This work was supported in part by funding to Forefront, a collaborative research group dedicated to the study of frontotemporal dementia and motor neuron disease, from the National Health and Medical Research Council (NHMRC) of Australia program grant (APP1037746) and the Australian Research Council (ARC) Centre of Excellence in Cognition and its Disorders Memory Program (CE110001021). MI is supported by an ARC Future Fellowship (FT160100096). FK is supported by an NHMRCARC Dementia Research Development Fellowship (APP1097026). YC is supported by the State Scholarship Fund of China (No. 201608200010). OP is supported by an NHMRC Senior Research Fellowship (APP1103258).

Authors' disclosures available online (http:// j-alz.com/manuscript-disclosures/17-0809).

\section{SUPPLEMENTARY MATERIAL}

The supplementary material is available in the electronic version of this article: http://dx.doi.org/ 10.3233/JAD-170809. 


\section{REFERENCES}

[1] Baron-Cohen S (1995) Mindblindness: An essay on autism and theory of mind, MIT Press, Cambridge.

[2] Heider F, Simmel M (1944) An experimental study of apparent behavior. Am J Psychol 57, 243-259.

[3] Castelli F, Happe F, Frith U, Frith C (2000) Movement and mind: A functional imaging study of perception and interpretation of complex intentional movement patterns. Neuroimage 12, 314-325.

[4] Schaafsma SM, Pfaff DW, Spunt RP, Adolphs R (2015) Deconstructing and reconstructing theory of mind. Trends Cogn Sci 19, 65-72.

[5] Happé F, Cook JL, Bird G (2017) The structure of social cognition: In(ter)dependence of sociocognitive processes. Annu Rev Psychol 68, 243-267.

[6] Adenzato M, Cavallo M, Enrici I (2010) Theory of mind ability in the behavioural variant of frontotemporal dementia: An analysis of the neural, cognitive, and social levels. Neuropsychologia 48, 2-12.

[7] Rascovsky K, Hodges JR, Knopman D, Mendez MF, Kramer JH, Neuhaus J, van Swieten JC, Seelaar H, Dopper EG, Onyike CU, Hillis AE, Josephs KA, Boeve BF, Kertesz A, Seeley WW, Rankin KP, Johnson JK, Gorno-Tempini ML, Rosen H, Prioleau-Latham CE, Lee A, Kipps CM, Lillo P, Piguet O, Rohrer JD, Rossor MN, Warren JD, Fox NC, Galasko D, Salmon DP, Black SE, Mesulam M, Weintraub S, Dickerson BC, Diehl-Schmid J, Pasquier F, Deramecourt V, Lebert F, Pijnenburg Y, Chow TW, Manes F, Grafman J, Cappa SF, Freedman M, Grossman M, Miller BL (2011) Sensitivity of revised diagnostic criteria for the behavioural variant of frontotemporal dementia. Brain 134, 2456-2477.

[8] Lough S, Kipps C, Treise C, Watson P, Blair J, Hodges J (2006) Social reasoning, emotion and empathy in frontotemporal dementia. Neuropsychologia 44, 950-958.

[9] Dermody N, Wong S, Ahmed R, Piguet O, Hodges JR, Irish $M$ (2016) Uncovering the neural bases of cognitive and affective empathy deficits in Alzheimer's disease and the behavioral-variant of frontotemporal dementia. J Alzheimers Dis 53, 801-816.

[10] Kumfor F, Irish M, Hodges JR, Piguet O (2013) The orbitofrontal cortex is involved in emotional enhancement of memory: Evidence from the dementias. Brain 136, 2992-3003.

[11] Kipps CM, Nestor PJ, Acosta-Cabronero J, Arnold R, Hodges JR (2009) Understanding social dysfunction in the behavioural variant of frontotemporal dementia: The role of emotion and sarcasm processing. Brain 132, 592-603.

[12] Rankin KP, Gorno-Tempini ML, Allison SC, Stanley CM, Glenn S, Weiner MW, Miller BL (2006) Structural anatomy of empathy in neurodegenerative disease. Brain 129, 29452956.

[13] O'Callaghan C, Bertoux M, Irish M, Shine JM, Wong S, Spiliopoulos L, Hodges JR, Hornberger M (2016) Fair play: Social norm compliance failures in behavioural variant frontotemporal dementia. Brain 139, 204-216.

[14] Mendez MF, Fong SS, Shapira JS, Jimenez EE, Kaiser NC, Kremen SA, Tsai PH (2014) Observation of social behavior in frontotemporal dementia. Am J Alzheimers Dis Other Demen 29, 215-221.

[15] Seeley WW, Crawford R, Rascovsky K, Kramer JH, Weiner M, Miller BL, Gorno-Tempini ML (2008) Frontal paralimbic network atrophy in very mild behavioral variant frontotemporal dementia. Arch Neurol 65, 249-255.
[16] Rabinovici GD, Seeley WW, Kim EJ, Gorno-Tempini ML, Rascovsky K, Pagliaro TA, Allison SC, Halabi C, Kramer JH, Johnson JK, Weiner MW, Forman MS, Trojanowski JQ, Dearmond SJ, Miller BL, Rosen HJ (2007) Distinct MRI atrophy patterns in autopsy-proven Alzheimer's disease and frontotemporal lobar degeneration. Am J Alzheimers Dis Other Demen 22, 474-488.

[17] Irish M, Piguet O, Hodges JR (2012) Self-projection and the default network in frontotemporal dementia. Nat Rev Neurol 8, 152-161.

[18] Gallagher H, Frith C (2003) Functional imaging of "theory of mind". Trends Cogn Sci 7, 77-83.

[19] Gregory C, Lough S, Stone V, Erzinclioglu S, Martin L, Baron-Cohen S, Hodges JR (2002) Theory of mind in patients with frontal variant frontotemporal dementia and Alzheimer's disease: Theoretical and practical implications. Brain 125, 752-764.

[20] Kipps CM, Hodges JR (2006) Theory of mind in frontotemporal dementia. Soc Neurosci 1, 235-244.

[21] Eslinger PJ, Moore P, Troiani V, Antani S, Cross K, Kwok S, Grossman M (2007) Oops! Resolving social dilemmas in frontotemporal dementia. J Neurol Neurosurg Psychiatry 78, 457-460.

[22] Fernandez-Duque D, Baird JA, Black SE (2009) Falsebelief understanding in frontotemporal dementia and Alzheimer's disease. J Clin Exp Neuropsychol 31, 489-497.

[23] Le Bouc R, Lenfant P, Delbeuck X, Ravasi L, Lebert F, Semah F, Pasquier F (2012) My belief or yours? Differential theory of mind deficits in frontotemporal dementia and Alzheimer's disease. Brain 135, 3026-3038.

[24] Shany-Ur T, Poorzand P, Grossman SN, Growdon ME, Jang JY, Ketelle RS, Miller BL, Rankin KP (2012) Comprehension of insincere communication in neurodegenerative disease: Lies, sarcasm, and theory of mind. Cortex 48, 13291341.

[25] Irish M, Hodges JR, Piguet O (2014) Right anterior temporal lobe dysfunction underlies theory of mind impairments in semantic dementia. Brain 137, 1241-1253.

[26] Clark CN, Nicholas JM, Henley SM, Downey LE, Woollacott IO, Golden HL, Fletcher PD, Mummery CJ, Schott JM, Rohrer JD, Crutch SJ, Warren JD (2015) Humour processing in frontotemporal lobar degeneration: A behavioural and neuroanatomical analysis. Cortex $\mathbf{6 9}, 47-59$.

[27] Torralva T, Kipps CM, Hodges JR, Clark L, Bekinschtein T, Roca M, Calcagno ML, Manes F (2007) The relationship between affective decision-making and theory of mind in the frontal variant of fronto-temporal dementia. Neuropsychologia 45, 342-349.

[28] Torralva T, Roca M, Gleichgerrcht E, Bekinschtein T, Manes F (2009) A neuropsychological battery to detect specific executive and social cognitive impairments in early frontotemporal dementia. Brain 132, 1299-1309.

[29] Gleichgerrcht E, Torralva T, Roca M, Pose M, Manes F (2011) The role of social cognition in moral judgment in frontotemporal dementia. Soc Neurosci 6, 113-122.

[30] Funkiewiez A, Bertoux M, de Souza LC, Levy R, Dubois B (2012) The SEA (Social cognition and Emotional Assessment): A clinical neuropsychological tool for early diagnosis of frontal variant of frontotemporal lobar degeneration. Neuropsychology 26, 81-90.

[31] Kumfor F, Irish M, Leyton C, Miller L, Lah S, Devenney E, Hodges JR, Piguet O (2014) Tracking the progression of social cognition in neurodegenerative disorders. $J$ Neurol Neurosurg Psychiatry 85, 1076-1083. 
[32] Rankin KP, Salazar A, Gorno-Tempini ML, Sollberger M, Wilson SM, Pavlic D, Stanley CM, Glenn S, Weiner MW, Miller BL (2009) Detecting sarcasm from paralinguistic cues: Anatomic and cognitive correlates in neurodegenerative disease. Neuroimage 47, 2005-2015.

[33] Dodich A, Cerami C, Crespi C, Canessa N, Lettieri G, Iannaccone S, Marcone A, Cappa SF, Cacioppo JT (2016) Differential impairment of cognitive and affective mentalizing abilities in neurodegenerative dementias: Evidence from behavioral variant of frontotemporal dementia, Alzheimer's disease, and mild cognitive impairment. J Alzheimers Dis 50, 1011-1022.

[34] Torralva T, Gleichgerrcht E, Torres Ardila MJ, Roca M, Manes FF (2015) Differential cognitive and affective theory of mind abilities at mild and moderate stages of behavioral variant frontotemporal dementia. Cogn Behav Neurol 28, 63-70.

[35] McKhann GM, Knopman DS, Chertkow H, Hyman BT, Jack CR Jr, Kawas CH, Klunk WE, Koroshetz WJ, Manly JJ, Mayeux R, Mohs RC, Morris JC, Rossor MN, Scheltens P, Carrillo MC, Thies B, Weintraub S, Phelps $\mathrm{CH}$ (2011) The diagnosis of dementia due to Alzheimer's disease: Recommendations from the National Institute on Aging-Alzheimer's Association workgroups on diagnostic guidelines for Alzheimer's disease. Alzheimers Dement 7, 263-269.

[36] Ramanan S, de Souza LC, Moreau N, Sarazin M, Teixeira AL, Allen Z, Guimaraes HC, Caramelli P, Dubois B, Hornberger M, Bertoux M (2017) Determinants of theory of mind performance in Alzheimer's disease: A data-mining study. Cortex $\mathbf{8 8}, 8-18$

[37] Bora E, Walterfang M, Velakoulis D (2015) Theory of mind in behavioural-variant frontotemporal dementia and Alzheimer's disease: A meta-analysis. J Neurol Neurosurg Psychiatry 86, 714-719.

[38] Bertoux M, de Souza LC, O'Callaghan C, Greve A, Sarazin M, Dubois B, Hornberger M (2016) Social cognition deficits: The key to discriminate behavioral variant frontotemporal dementia from Alzheimer's disease regardless of amnesia? J Alzheimers Dis 49, 1065-1074.

[39] Irish M, Piguet O, Hodges JR, Hornberger M (2014) Common and unique grey matter correlates of episodic memory dysfunction in frontotemporal dementia and Alzheimer's disease. Hum Brain Mapp 35, 1422-1435.

[40] Irish M, Hornberger M, Lah S, Miller L, Pengas G, Nestor PJ, Hodges JR, Piguet O (2011) Profiles of recent autobiographical memory retrieval in semantic dementia, behavioural-variant frontotemporal dementia, and Alzheimer's disease. Neuropsychologia 49, 2694-2702.

[41] Wong S, Bertoux M, Savage G, Hodges JR, Piguet O, Hornberger M (2016) Comparison of prefrontal atrophy and episodic memory performance in dysexecutive Alzheimer's disease and behavioral-variant frontotemporal dementia. J Alzheimers Dis 51, 889-903.

[42] Ramanan S, Bertoux M, Flanagan E, Irish M, Piguet O, Hodges JR, Hornberger M (2017) Longitudinal executive function and episodic memory profiles in behavioral-variant frontotemporal dementia and Alzheimer's disease. J Int Neuropsychol Soc 23, 34-43.

[43] Apperly IA (2012) What is "theory of mind"? Concepts, cognitive processes and individual differences. $Q J$ Exp Psychol (Hove) 65, 825-839.

[44] Rakoczy H, Harder-Kasten A, Sturm L (2012) The decline of theory of mind in old age is (partly) mediated by developmental changes in domain-general abilities. $\mathrm{Br} J$ Psychol 103, 58-72.

[45] Schurz M, Radua J, Aichhorn M, Richlan F, Perner J (2014) Fractionating theory of mind: A meta-analysis of functional brain imaging studies. Neurosci Biobehav Rev 42, 9-34.

[46] Bertoux M, O'Callaghan C, Dubois B, Hornberger M (2016) In two minds: Executive functioning versus theory of mind in behavioural variant frontotemporal dementia. $J$ Neurol Neurosurg Psychiatry 87, 231-234.

[47] Williams GB, Nestor PJ, Hodges JR (2005) Neural correlates of semantic and behavioural deficits in frontotemporal dementia. Neuroimage 24, 1042-1051.

[48] White SJ, Coniston D, Rogers R, Frith U (2011) Developing the Frith-Happe animations: A quick and objective test of Theory of Mind for adults with autism. Autism Res 4, 149-154.

[49] Abell F, Happé F, Frith U (2000) Do triangles play tricks? Attribution of mental states to animated shapes in normal and abnormal development. Cogn Dev 15, 1-16.

[50] Mioshi E, Hsieh S, Savage S, Hornberger M, Hodges JR (2010) Clinical staging and disease progression in frontotemporal dementia. Neurology 74, 1591-1597.

[51] Hsieh S, Schubert S, Hoon C, Mioshi E, Hodges JR (2013) Validation of the Addenbrooke's Cognitive Examination III in frontotemporal dementia and Alzheimer's disease. Dement Geriatr Cogn Disord 36, 242-250.

[52] Morris J (1997) Clinical dementia rating: A reliable and valid diagnostic and staging measure for dementia of the Alzheimer type. Int Psychogeriatr 9, 173-176.

[53] Wechsler D (1997) WAIS-III administration and scoring manual, The Psychological Corporation, San Antonio.

[54] Reitan R (1958) Validity of the Trail Making Test as an indicator of organic brain damage. Percept Mot Skills $\mathbf{8}$, 271-276.

[55] Burgess P, Shallice T (1997) The Hayling and Brixton Tests, Thames Valley Test Company, Thurston Suffolk.

[56] Schmidt M (1996) Rey Auditory and Verbal Learning Test: A handbook, Western Psychological Services, Los Angeles.

[57] Rey A (1941) L'examen psychologique dans les cas d'encéphalopathie traumatique. Arch Psychol 28, 215-285.

[58] Wedderburn C, Wear H, Brown J, Mason SJ, Barker RA, Hodges JR, Williams-Gray C (2008) The utility of the Cambridge Behavioural Inventory in neurodegenerative disease. J Neurol Neurosurg Psychiatry 79, 500-503.

[59] Davis MH (1983) Measuring individual differences in empathy: Evidence for a multidimensional approach. J Pers Soc Psychol 44, 113-126.

[60] Ashburner J, Friston KJ (2000) Voxel-based morphometry - the methods. Neuroimage 11, 805-821.

[61] Mechelli A, Price CJ, Friston CJ, Ashburner J (2005) Voxel-based morphometry of the human brain: Methods and applications. Curr Med Imaging Rev 1, 1-9.

[62] Smith SM, Jenkinson M, Woolrich MW, Beckmann CF, Behrens TE, Johansen-Berg H, Bannister PR, De Luca M, Drobnjak I, Flitney DE, Niazy RK, Saunders J, Vickers J, Zhang Y, De Stefano N, Brady JM, Matthews PM (2004) Advances in functional and structural MR image analysis and implementation as FSL. Neuroimage 23(Suppl 1), S208-S219.

[63] Smith SM (2002) Fast robust automated brain extraction. Hum Brain Mapp 17, 143-155.

[64] Zhang Y, Brady M, Smith S (2001) Segmentation of brain MR images through a hidden Markov random field model and the expectation-maximization algorithm. IEEE Trans Med Imaging 20, 45-57. 
[65] Andersson JLR, Jenkinson M, Smith S (2007) Non-linear optimisation. FMRIB Technical Report TR07JA1, University of Oxford FMRIB Centre.

[66] Andersson JLR, Jenkinson M, Smith S (2007) Non-linear registration, aka Spatial normalisation. FMRIB Technical Report TR07JA2, University of Oxford FMRIB Centre.

[67] Rueckert D, Sonoda LI, Hayes C, Hill DL, Leach MO, Hawkes DJ (1999) Nonrigid registration using free-form deformations: Application to breast MR images. IEEE Trans Med Imaging 18, 712-721.

[68] Lieberman MD, Cunningham WA (2009) Type I and Type II error concerns in fMRI research: Re-balancing the scale. Soc Cogn Affect Neurosci 4, 423-428.

[69] Landin-Romero R, Kumfor F, Leyton CE, Irish M, Hodges JR, Piguet O (2017) Disease-specific patterns of cortical and subcortical degeneration in a longitudinal study of Alzheimer's disease and behavioural-variant frontotemporal dementia. Neuroimage 151, 72-80.

[70] Irish M, Addis DR, Hodges JR, Piguet O (2012) Considering the role of semantic memory in episodic future thinking: Evidence from semantic dementia. Brain 135, 2178-2191.

[71] Dermody N, Hornberger M, Piguet O, Hodges JR, Irish M (2015) Prospective memory impairments in Alzheimer's disease and behavioral variant frontotemporal dementia clinical and neural correlates. $J$ Alzheimers Dis 50, 425-441.

[72] Pardini M, Emberti Gialloreti L, Mascolo M, Benassi F, Abate L, Guida S, Viani E, Dal Monte O, Schintu S, Krueger F, Cocito L (2013) Isolated theory of mind deficits and risk for frontotemporal dementia: A longitudinal pilot study. J Neurol Neurosurg Psychiatry 84, 818-821.

[73] Snowden JS, Gibbons ZC, Blackshaw A, Doubleday E, Thompson J, Craufurd D, Foster J, Happe F, Neary D (2003) Social cognition in frontotemporal dementia and Huntington's disease. Neuropsychologia 41, 688-701.

[74] Roca M, Torralva T, Gleichgerrcht E, Woolgar A, Thompson R, Duncan J, Manes F (2011) The role of Area 10 (BA10) in human multitasking and in social cognition: A lesion study. Neuropsychologia 49, 3525-3531.

[75] Hsieh S, Irish M, Daveson N, Hodges JR, Piguet O (2013) When one loses empathy: Its effect on carers of patients with dementia. J Geriatr Psychiatry Neurol 26, 174-184.

[76] Helmes E, Ostbye T (2002) Beyond memory impairment: Cognitive changes in Alzheimer's disease. Arch Clin Neuropsychol 17, 179-193.

[77] Leslie FV, Foxe D, Daveson N, Flannagan E, Hodges JR, Piguet O (2016) Frontier Executive Screen: A brief executive battery to differentiate frontotemporal dementia and Alzheimer's disease. J Neurol Neurosurg Psychiatry 87, 831-835.

[78] Molenberghs P, Johnson H, Henry JD, Mattingley JB (2016) Understanding the minds of others: A neuroimaging metaanalysis. Neurosci Biobehav Rev 65, 276-291.

[79] Lewis PA, Birch A, Hall A, Dunbar RI (2017) Higher order intentionality tasks are cognitively more demanding. Soc Cogn Affect Neurosci 12, 1063-1071.

[80] Seeley WW, Menon V, Schatzberg AF, Keller J, Glover GH, Kenna H, Reiss AL, Greicius MD (2007) Dissociable intrinsic connectivity networks for salience processing and executive control. J Neurosci 27, 2349-2356.

[81] Seeley WW (2008) Selective functional, regional, and neuronal vulnerability in frontotemporal dementia. Curr Opin Neurol 21, 701-707.
[82] Seeley WW, Allman JM, Carlin DA, Crawford RK, Macedo MN, Greicius MD, Dearmond SJ, Miller BL (2007) Divergent social functioning in behavioral variant frontotemporal dementia and Alzheimer disease: Reciprocal networks and neuronal evolution. Alzheimer Dis Assoc Disord 21, S50-S57.

[83] Abu-Akel A, Shamay-Tsoory S (2011) Neuroanatomical and neurochemical bases of theory of mind. Neuropsychologia 49, 2971-2984.

[84] Sripada CS, Angstadt M, Banks S, Nathan PJ, Liberzon I, Phan KL (2009) Functional neuroimaging of mentalizing during the trust game in social anxiety disorder. Neuroreport 20, 984-989.

[85] Simpson EH, Kellendonk C, Kandel E (2010) A possible role for the striatum in the pathogenesis of the cognitive symptoms of schizophrenia. Neuron 65, 585-596.

[86] Goto Y, Grace AA (2005) Dopaminergic modulation of limbic and cortical drive of nucleus accumbens in goal-directed behavior. Nat Neurosci 8, 805-812.

[87] Bertoux M, O'Callaghan C, Flanagan E, Hodges JR, Hornberger M (2015) Fronto-striatal atrophy in behavioral variant frontotemporal dementia and Alzheimer's disease. Front Neurol 6, 147.

[88] Beadle JN, Tranel D, Cohen NJ, Duff MC (2013) Empathy in hippocampal amnesia. Front Psychol 4, 69.

[89] Olson IR, Page K, Moore KS, Chatterjee A, Verfaellie M (2006) Working memory for conjunctions relies on the medial temporal lobe. J Neurosci 26, 4596-4601.

[90] Barense MD, Gaffan D, Graham KS (2007) The human medial temporal lobe processes online representations of complex objects. Neuropsychologia 45, 2963-2974.

[91] Cohn M, St-Laurent M, Barnett A, McAndrews MP (2015) Social inference deficits in temporal lobe epilepsy and lobectomy: Risk factors and neural substrates. Soc Cogn Affect Neurosci 10, 636-644.

[92] Van Overwalle F, Baetens K, Marien P, Vandekerckhove M (2014) Social cognition and the cerebellum: A metaanalysis of over 350 fMRI studies. Neuroimage 86, 554-572.

[93] Mothersill O, Knee-Zaska C, Donohoe G (2016) Emotion and theory of mind in schizophrenia-investigating the role of the cerebellum. Cerebellum 15, 357-368.

[94] D'Mello AM, Stoodley CJ (2015) Cerebro-cerebellar circuits in autism spectrum disorder. Front Neurosci 9, 408.

[95] Guo CC, Tan R, Hodges JR, Hu X, Sami S, Hornberger M (2016) Network-selective vulnerability of the human cerebellum to Alzheimer's disease and frontotemporal dementia. Brain 139, 1527-1538.

[96] Tan RH, Devenney E, Kiernan MC, Halliday GM, Hodges JR, Hornberger M (2015) Terra incognita-cerebellar contributions to neuropsychiatric and cognitive dysfunction in behavioral variant frontotemporal dementia. Front Aging Neurosci 7, 121.

[97] Stoodley CJ, Schmahmann JD (2009) Functional topography in the human cerebellum: A meta-analysis of neuroimaging studies. Neuroimage $\mathbf{4 4}, 489-501$.

[98] Ahmed RM, Devenney EM, Irish M, Ittner A, Naismith S, Ittner LM, Rohrer JD, Halliday GM, Eisen A, Hodges JR, Kiernan MC (2016) Neuronal network disintegration: Common pathways linking neurodegenerative diseases. J Neurol Neurosurg Psychiatry 87, 1234-1241.

[99] Konarski JZ, McIntyre RS, Grupp LA, Kennedy SH (2005) Is the cerebellum relevant in the circuitry of neuropsychiatric disorders? J Psychiatry Neurosci 30, 178-186. 